\title{
Dez Anos de Evolução da Agricultura Familiar no Brasil: (1996 e 2006) ${ }^{1}$
}

\author{
Carlos Enrique Guanziroli ${ }^{2}$, Antonio Marcio Buainain ${ }^{3}$ e \\ Alberto Di Sabbato ${ }^{4}$
}

\begin{abstract}
Resumo: Este artigo compara os principais resultados do censo agropecuário do IBGE de 1996 com os resultados do censo de 2006, seguindo a metodologia conhecida como "FAO-Incra" que permite caracterizar a agricultura familiar delimitando-a no universo total dos estabelecimentos. Na comparação destacam-se algumas variáveis significativas, tais como participação no valor da produção total (VBP), participação na área total dos estabelecimentos, utilização de tecnologia moderna e produtividade parcial de fatores.Os censos mostram que a participação na produção agropecuária se manteve praticamente inalterada, passando de 37,91\% em 1996 para 36,11\% em 2006, numa década de forte expansão do setor, o que revela que este segmente faz parte das cadeias produtivas agropecuárias do agronegócio brasileiro. A agricultura familiar é um segmento heterogêneo, com diversos subsegmentos. Nos dez anos de pesquisa percebe-se que houve forte crescimento da participação na produção do segmento mais abastado da agricultura familiar (A) e um crescimento numérico dos grupos mais pobres da mesma (C e D), sem o correspondente acréscimo de produção.
\end{abstract}

Palavras-chaves: agricultura familiar, inovações tecnológicas, produtividade agropecuária.

\begin{abstract}
This article compares the main findings of data fromBrazilian agricultural census in 1996 with the same in 2006 by applying the methodology known as "FAO/Incra", which allows characterizing family farm in relation to the total universe of farms. In this comparison, several variables are presented, such as the participation of family farming in the total value of production, in the total number of farms, utilization of modern technology and partial factor productivity. Their share of total agricultural production stayed almost equal, with slight reduction, from 37.91\% in 1996 to 36,11\% during a decade of sharp expansion of agriculture as a whole, demonstrating that this segment is integrated in
\end{abstract}

\footnotetext{
1 Este trabalho foi realizado sob os auspícios do convênio Nead/IICA/UFF, assinado recentemente entre estas entidades com o objetivo de analisar e caracterizar a agricultura familiar com base no censo agropecuário do IBGE de 2006 de forma comparada com o censo de 1995-1996.

2 Professor Associado III da Faculdade de Economia/UFF. E-mail: carlos.guanzi@gmail.com.

3 Professor Livre Docente do Instituto de Economia/Unicamp. E-mail: buainain@gmail.com.

4 Professor Associado II da Faculdade de Economia/UFF. E-mail: alberto@economia.uff.br.
} 
the productive agricultural chains of the Brazilian agribusiness. Family farming is a heterogeneous segment, with different segments. During the period of ten years, the richestof these segments (A) has increased their participation inthe total production, while the poorest sub segments $(C$ and $D)$ have only grown in absolute terms without a corresponding increase in production.

Key-words: family farming, technological innovation, agricultural yield.

Classificação JEL: Q15, R20.

\section{Introdução}

Em 2000, o Convênio FAO/Incra, em conjunto com o MDA, apresentou o estudo Novo Retrato da Agricultura Familiar: o Brasil Redescoberto (MDA/ FAO, 2000), que mostrou ao País uma realidade distinta sobre a importância e a contribuição da agricultura familiar para o desenvolvimento do Brasil.

Até aquele momento, a "pequena produção" era principalmente vista como um conjunto de unidades de subsistência que comercializavam excedentes nos mercados locais. Alguns autores destacavam a pequena produção e a unidade familiar como "depósito e reserva de mão de obra" que, com baixo custo de oportunidade, inseria-se no mercado de trabalho rural como trabalhador temporário, conhecido como boia-fria.

O estudo atualizava a fotografia da agricultura brasileira em geral e focava e destacava a categoria da agricultura familiar que, até então, não tinha sido utilizada de forma abrangente no País. Em segundo lugar, o trabalho revelou uma agricultura familiar muito mais robusta e relevante do ponto de vista econômico e social do que aquela que era apresentada pela visão dominante da "pequena produção de subsistência".

Deve-se lembrar que ser agricultor familiar não tem nenhuma conotação de superioridade em relação aos não familiares, trata-se apenas de diferenciar uma categoria que baseia sua produção no uso preferencial da mão de obra familiar e que exerce a gestão do empreendimento de forma direta, presencial, por meio de algum dos familiares envolvidos na produção.
Os não familiares, distintamente, usam trabalho assalariado, o que é positivo porque gera emprego, mas fazem a gestão do empreendimento por meio de administradores, de longe.

Os traços marcantes da fotografia revelada pelo estudo foram amplamente difundidos nestes últimos dez anos. Mas, passados dez anos do lançamento do Pronaf, qual será a situação da agricultura familiar: será que ela conservou o dinamismo revelado em 1996 ?

A realização do censo agropecuário pelo IBGE em 2006 permite dar resposta a algumas dessas inquietudes e isso é feito nas seções 3 e 4 deste trabalho, em que se faz uma análise comparativa da evolução da agricultura familiar entre os dois censos e uma análise do processo de modernização da agricultura familiar por meio da evolução de algumas variáveis selecionadas. Na parte conclusiva sumariam-se alguns fatores que teriam contribuído para o desempenho da agricultura familiar em diversos aspectos.

\section{Marco metodológico}

Do ponto de vista legal (Lei n. 11.326 de 2006), agricultor familiar é aquele que pratica atividades no meio rural e que cumpre os seguintes quesitos:

I - não deter área maior do que quatro módulos fiscais ${ }^{5}$; II - utilizar predominantemente

5 O módulo fiscal é uma unidade relativa de área, expressa em hectares, fixada para cada município, instituída pela Lei n. 6.746, de 10 de dezembro de 1979, que leva em conta:

- tipo de exploração predominante no município;

- a renda obtida com a exploração predominante; 
mão de obra da própria família nas atividades do seu estabelecimento ou empreendimento; III - a renda familiar ser predominantemente originada de atividades vinculadas ao próprio estabelecimento e IV - o estabelecimento ser dirigido pelo agricultor (a) com sua família (art.3).

Esta lei inspirou-se no trabalho conhecido como "FAO/Incra: Novo Retrato da Agricultura Familiar" - Guanziroli. C. et al. (2001), que caracterizava o universo familiar como aquele integrado pelos estabelecimentos que atendiam, simultaneamente, às seguintes condições: a direção dos trabalhos do estabelecimento é exercida pelo produtor; o trabalho familiar é superior ao trabalho contratado e que não houvesse estabelecimentos com área superior a uma área máxima regional, estabelecida em 15 módulos fiscais.

O trabalho FAO/Incra, como se vê, amplia o escopo para agricultores de tamanho médio - até 15 módulos fiscais - enquanto, nos critérios da lei, o conceito restringe-se aos pequenos produtores rurais - até quatro módulos fiscais.

Neste trabalho o universo familiar foi caracterizado pelos estabelecimentos que atendiam, simultaneamente, às seguintes condições:

a) a direção dos trabalhos do estabelecimento era exercida pelo produtor;

b) o trabalho familiar era superior ao trabalho contratado.

Adicionalmente, foi estabelecida uma área máxima regional como limite superior para a área total dos estabelecimentos familiares ${ }^{6}$. Tal limite

- outras explorações existentes no município que, embora não predominantes, sejam expressivas em função da renda ou da área utilizada;

- conceito de propriedade familiar.

6 Essa área máxima regional foi obtida do modo exposto a seguir. Foram consideradas as áreas dos módulos fiscais municipais, segundo a tabela do Incra. Calculou-se a área de um módulo médio ponderado, segundo o número de municípios em que incide cada área de módulo fiscal municipal, para cada unidade da federação. A partir desse "módulo médio ponderado estadual", foi calculado um módulo médio para cada grande região do País. O "módulo médio regional" foi multiplicado por 15 para teve por fim evitar eventuais distorções que decorreriam da inclusão de grandes latifúndios no universo de unidades familiares, ainda que do ponto de vista conceitual a agricultura familiar não seja definida a partir do tamanho do estabelecimento, cuja extensão máxima é determinada pelo que a família pode explorar com base em seu próprio trabalho associado à tecnologia de que dispõe.

A primeira condição é obtida diretamente da resposta a um simples quesito do questionário censitário, ao passo que, para a obtenção da segunda condição, é necessário recorrer a um conjunto de operações envolvendo inclusive variáveis externas ao censo, tendo em vista não só a inadequação das informações censitárias para o caso, como também a complexidade conceitual e operacional de que se reveste o tema.

Noque se refere à determinação da quantidade de trabalho, tanto familiar quanto contratado, $\mathrm{o}$ ideal seria que se pudesse determinar o número de homens-hora trabalhado, de modo a determinar com maior exatidão a efetiva carga de trabalho de cada uma das categorias de trabalhadores.

Para o caso do trabalho familiar, entretanto, pode-se supor que a informação sobre o número de pessoas ocupadas da família na atividade produtiva ${ }^{7}$ reflete, com razoável precisão, a carga de trabalho efetivamente empregada. Desse modo, considerou-se como de tempo integral o trabalho do "responsável", que é o produtor familiar que, simultaneamente, administra o seu estabelecimento ${ }^{8}$ e o dos "membros não remunerados" com 14 ou mais anos de idade. Para evitar superestimação do trabalho familiar, computou-se pela metade o pessoal ocupado

determinação da área máxima regional, com o que se procurou estabelecer uma aproximação com o que dispõe a legislação, tendo em vista que o limite máximo legal da propriedade média é de 15 módulos fiscais.

7 A categoria de pessoal ocupado do censo relativa ao trabalho familiar intitula-se "responsável e membros não remunerados da família".

8 De acordo com as instruções de preenchimento do questionário do censo, é obrigatório o registro de pelo menos uma pessoa na categoria "responsável e membros não remunerados da família" (ver IBGE. Censo Agropecuário - Manual do Recenseador, p. 42-43). 
da família com menos de 14 anos $^{9}$, não apenas em virtude da sua menor capacidade de trabalho, como também pela possibilidade de envolvimento em outras atividades, como, por exemplo, as escolares. Assim, foi calculado o número de Unidades de Trabalho Familiar (UTF), por estabelecimento/ano, como sendo a soma do número de pessoas ocupadas da família com 14 anos e mais e da metade do número de pessoas ocupadas da família com menos de 14 anos.

Em relação ao trabalho contratado, as informações censitárias são claramente inadequadas, sobretudo as que se referem ao pessoal temporário. De um lado, tem-se a informação do número de empregados permanentes, temporários e parceiros (empregados) numa determinada data ${ }^{10}$; de outro, é informado o número máximo de empregados temporários em cada mês do ano. Em ambos os casos, não se tem a informação da carga de trabalho efetivamente realizada, uma vez que não se dispõe do número de meses ou dias trabalhados. Poder-se-ia, para os empregados permanentes e parceiros empregados, fazer suposição semelhante à que se fez para o trabalho familiar. Entretanto, tal suposição seria completamente equivocada para os empregados temporários ${ }^{11}$. Além disso, o censo não possui informação sobre a quantidade de mão de obra empregada indiretamente, sob o regime de empreitada. Dessa forma, optou-se pela obtenção do trabalho contratado a partir das despesas realizadas com mãodeobra empregada, incluindo os serviços de empreitada de mãodeobra. O valor dessas despesas dividido pelo valor anual de remuneração de uma unidade de mão de obra

$9 \quad$ Foram utilizados os limites de idade disponíveis no censo.

10 No censo agropecuário de 1995-1996, a data de referência para os dados estruturais foi 31/12/1995 (ver IBGE. Censo Agropecuário 1995-1996 - número 1 - Brasil. Rio de Janeiro, 1998, p. 35).

11 Tal afirmação pode se respaldar em um exemplo simples: para uma mesma jornada de trabalho, um empregado temporário trabalhando durante 30 dias equivale, em homens-hora de trabalho, a 30 empregados temporários trabalhando durante um dia. Entretanto, tal como estão dispostas as informações, haveria uma forte divergência entre o primeiro caso (uma unidade de trabalho) e o segundo (30 unidades de trabalho). permite obter o número de unidades de trabalho contratadas pelo estabelecimento.

Operacionalmente, o número de Unidades de Trabalho Contratada (UTC) foi calculado da seguinte forma:

1. obteve-se o valor total das despesas com mão de obra contratada pela soma de: a) valor das despesas com o pagamento (em dinheiro ou em produtos) da mãodeobra assalariada (permanente ou temporária); b) valor das despesas com o pagamento efetuado a parceiros empregados ${ }^{12}$; c) valor das despesas com o pagamento de serviços de empreitada com fornecimento só de mão de obra;

2. calculou-se o valor do custo médio anual de um empregado no meio rural, mediante a multiplicação do valor da diária média estadual $^{13}$ de um trabalhador rural pelo número de dias úteis trabalhados no ano, calculado em 260;

3. por fim, determinou-se o número de Unidades de Trabalho Contratado (UTC), por estabelecimento/ano, como sendo a divisão do valor total das despesas com mãodeobra contratada pelo valor do custo médio anual de um empregado no meio rural.

Os gastos com serviços de empreitada de mão de obra foram incluídos no cálculo do trabalho não familiar, tal como indicado acima, a fim de evitar a inclusão de formas típicas de contratação informal de mão de obra através de "gatos", empreiteiros etc., utilizadas por unidades patronais, muitas vezes com o objetivo de eludir obrigações previstas na legislação trabalhista.

12 Esse valor foi calculado, segundo o IBGE, mediante a conversão da cota-parte da produção (meia, terça, quarta etc.), tomando-se por base o preço que se obteria na venda dos produtos (ver IBGE. Censo Agropecuário - Manual do Recenseador, p. 76).

13 O valor da diária estadual foi obtido pelo cálculo da média dos valores informados de remuneração de diarista na agricultura para os meses de junho e dezembro de 1995e junho de 1996, segundo os dados do Centro de Estudos Agrícolas da Fundação Getúlio Vargas. 
Quadro 1. Resumindo a metodologia de delimitação do universo familiar.

\begin{tabular}{|c|}
\hline Caracterização dos agricultores familiares \\
\hline Direção dos trabalhos do estabelecimento é do produtor e \\
UTF $>$ UTC e \\
Área total do estabelecimento $\leq$ área máxima regional \\
Unidade de Trabalho Familiar (UTF) \\
Pessoal ocupado da família de 14 anos e mais \\
+ \\
(Pessoal ocupado da família de menos de 14 anos) $/ 2$ \\
Unidade de Trabalho Contratado (UTC) \\
(Salários + Valor da quota-parte entregue a parceiros empregados + Serviços de empreitada de mão de obra) \\
$\div$ \\
(Diária estadual x 260)
\end{tabular}

No entanto, considerou-se que os gastos com serviços de empreitada com fornecimento de máquinas não deveriam entrar na massa salarial contratada por várias razões, entre as quais vale mencionar o fato de a empreita de serviços ser uma das características mais marcantes das unidades familiares nos países desenvolvidos. Este recurso permite às unidades familiares superarem a escassez de mão de obra e restrições de escala sem romper com sua natureza familiar. Além disso, trata-se de tendência inevitável do desenvolvimento econômico, da especialização das tarefas e do problema de escala que afeta em particular os estabelecimentos de menor porte, como é o caso da grande maioria do universo de produtores familiares.

A possibilidade de recorrer ao serviço de empreitada, particularmente para os casos que dificilmente podem ser eficientemente resolvidos via forma de cooperação direta entre produtores, facilita a viabilização da agricultura familiar. Por outro lado, é importante lembrar que os gastos com aluguel de máquinas e implementos agrícolas, não contratados em forma de empreitada, também não foram considerados como despesas com mão de obra.

Para definir um indicador de renda dos agricultores, levando-se em conta a produção para autoconsumo e à destinada ao mercado, considerando-se as informações disponíveis pelo censo, optou-se por trabalhar com a Renda Total
(RT) dos estabelecimentos. A Renda Total foi calculada como segue:

1. obteve-se o Valor Bruto - ajustado - da Produção (VBP*) do estabelecimento, calculado pela soma de: a) valor da produção vendida de milho ${ }^{14}$; b) valor da produção vendida dos principais produtos utilizados na indústria rural ${ }^{15}$; c) valor da produção colhida/obtida dos demais produtos animais e vegetais;

${ }^{14}$ De modo geral, deve-se considerar o valor bruto da produção colhida, já que a utilização da produção vendida elimina o consumo humano de produtos agrícolas e animais e desfigura um conjunto importante de sistemas caracterizados precisamente pelo elevado grau de "endogenia" e de aproveitamento de subprodutos. Estes sistemas estão presentes tanto em formas "atrasadas" (sistema roça/farinha/capoeira) como em formas "modernas" (sistema de criação avícola/milho/quintal). Este critério, no entanto, apresenta um problema, principalmente no caso do consumo intermediário de milho, que é largamente utilizado como alimento para animais. Neste caso, haveria dupla contagem, já que seria computado todo o milho colhido, assim como aquele que se "transforma" em suínos/aves que dele se alimentam. Para evitar este problema, o milho foi contabilizado a partir da produção vendida e não colhida.

15 Foram incluídos neste item os seguintes produtos: arroz em casca, café em coco, cana-de-açúcar, fumo em folha, leite e mandioca, quando havia informação de valor da produção dos respectivos produtos da indústria rural: arroz beneficiado em grão, café em grão, rapadura, fumo em rolo ou corda, queijo e farinha de mandioca. Este procedimento, que implica alguma imprecisão, foi o único possível, de vez que a informação sobre matéria-prima da indústria rural, existente nos censos agropecuários anteriores, foi suprimida no censo atual. 
Quadro 2. Resumindo a metodologia para o cálculo da Renda Total (RT) e de outros indicadores.

\begin{tabular}{|c|c|}
\hline Valor Bruto da Produção (VBP) & \\
\hline \multicolumn{2}{|l|}{$\sum$ Valor da produção colhida/obtida de todos os produtos animais e vegetais; } \\
\hline \multicolumn{2}{|l|}{ Renda Total (RT) } \\
\hline \multicolumn{2}{|l|}{ (VBP* + Receita Agropecuária Indireta + Valor da Produção da Indústria Rural) } \\
\hline \multicolumn{2}{|l|}{-} \\
\hline \multicolumn{2}{|l|}{ Valor Total das Despesas } \\
\hline \multicolumn{2}{|l|}{ VBP* } \\
\hline \multicolumn{2}{|c|}{$\sum$ Valor da produção vendida de milho e dos principais produtos utilizados na indústria rural } \\
\hline+ & \\
\hline \multicolumn{2}{|l|}{$\sum$ Valor da produção colhida/obtida dos demais produtos animais e vegetais } \\
\hline \multicolumn{2}{|l|}{ Receita Agropecuária Indireta } \\
\hline \multirow{3}{*}{\multicolumn{2}{|c|}{$\begin{array}{c}\text { Venda de esterco + Serviços prestados a terceiros + } \\
\text { + Venda de máquinas, veículos e implementos + Outras receitas provenientes do estabelecimento agrícola } \\
\text { Valor da Produção da Indústria Rural (VPIR) }\end{array}$}} \\
\hline & \\
\hline & \\
\hline \multicolumn{2}{|l|}{$\sum$ do valor da produção de todos os produtos da indústria rural* } \\
\hline \multicolumn{2}{|l|}{ Receita Agropecuária Total (RAT) } \\
\hline \multicolumn{2}{|l|}{ Receita Total - Receita de exploração mineral } \\
\hline Renda Monetária (RM) & \\
\hline (Receita Total - Receita de exploração mineral) - Despesa Total & \\
\hline
\end{tabular}

*O censo conceitua "indústria rural" como "as atividades de transformação ou beneficiamento de produtos agropecuários produzidos no estabelecimento ou adquiridos de terceiros, efetuados pelo produtor em instalações do próprio estabelecimento, comunitárias (moinhos, moendas, casas de farinha etc.) ou de terceiros por prestação de serviços".

2. calculou-se a Receita Agropecuária Indireta, composta pelas receitas provenientes de: venda de esterco; serviços prestados a terceiros; venda de máquinas, veículos e implementos; e outras receitas ${ }^{16}$;

3. obteve-se o Valor da Produção da Indústria Rural, informada diretamente pelo censo;

4. da soma dos três itens acima foi subtraído o Valor Total das Despesas, com o que, finalmente, determinou-se a Renda Total do estabelecimento.

\section{Evolução comparada da agricultura familiar 1996/2006}

Com base nesta metodologia foi feita a comparação da evolução da agricultura familiar entre os Censos Agropecuários do IBGE de 1996

16 É importante destacar que, à exceção da receita de exploração mineral, todas as receitas registradas pelo censo são provenientes, direta ou indiretamente, da atividade agropecuária do estabelecimento, não havendo, portanto, informação acerca de eventuais remunerações do produtor fora do estabelecimento, tais como salários, benefícios previdenciários etc. e 2006. Essa comparação revela que o número de agricultores familiares cresceu no decênio entre os censos, passando de 4.139 .000 para 4.551 .855 , o que representa $87,95 \%$ do total de estabelecimentos agropecuários do Brasil. O Valor Bruto da Produção dos agricultores familiares em 2006 foi de R\$ 59,2 bilhões, correspondente a 36,11\% da produção agropecuária total. Essa produção é realizada em $32 \%$ da área total dos estabelecimentos, totalizando 107 milhões de hectares.

Em termos de emprego (incluindo os membros da família e seus empregados), a agricultura familiar absorvia, em 2006, 13,04 milhões de pessoas, ou seja, $78,75 \%$ do total da mão de obra no campo.

A agricultura familiar, cuja importância econômica e social já havia sido revelada, ganhou mais espaço. Em relação ao censo de $1996^{17}$ houve, em 2006, como já mencionado, aumento no número de estabelecimentos familiares, bem como no pessoal ocupadoe na área ocupada por estes estabelecimentos, como mostra a Tabela 1.

\footnotetext{
17 Embora possa haver algumas diferenças metodológicas a serem consideradas.
} 
Tabela 1. Evolução da participação das principais variáveis da agricultura familiar-Brasil - 1996-2006.

\begin{tabular}{lcc}
\hline \multicolumn{1}{c}{ Variável } & $\mathbf{1 9 9 6}$ & $\mathbf{2 0 0 6}$ \\
\hline \% de estabelecimentos familiares & 85,17 & 87,95 \\
\% da área dos estabelecimentos familiares & 30,48 & 32,00 \\
$\%$ de VBP dos estabelecimentos familiares & 37,91 & 36,11 \\
\% do pessoal ocupado total dos estabelecimentos familiares & 76,85 & 78,75 \\
\hline
\end{tabular}

Fonte: Elaboração própria com base em IBGE, censos agropecuários 1995-1996 e 2006. Tabulações especiais.

Tabela 2. Participação percentual da agricultura familiarna produção regional - regiões do Brasil - 1996-2006.

\begin{tabular}{lll}
\hline \multicolumn{1}{c}{ Região } & $\mathbf{1 9 9 6}$ & $\mathbf{2 0 0 6}$ \\
\hline Norte & 58,26 & 60,18 \\
Nordeste & 42,98 & 47,38 \\
Sudeste & 24,43 & 22,28 \\
Sul & 57,13 & 54,43 \\
Centro-Oeste & 16,31 & 14,53 \\
\hline
\end{tabular}

Fonte: Elaboração própria com base em IBGE, censos agropecuários 1995-1996 e 2006. Tabulações especiais.

A participação no valor da produção teve um ligeiro decréscimo, passando de 37,91\% em 1996 para $36,61 \%$ em 2006.

A manutenção da participação da agricultura familiar na produção agropecuária (ou leve decréscimo), em uma década de forte expansão do setor, confirma a importância econômica deste segmento que, além de produzir alimentos, conseguiu crescer a quase o mesmo ritmo que asmais destacadas cadeias produtivas agropecuárias do campo brasileiro.

Essa participação fica revelada pelos dados do censo porque, nesta metodologia, os limites de área para ser considerado familiar são mais amplos que os da lei da agricultura familiar (que é de quatro módulos fiscais). Foi adotado um limite de área para cada região, que corresponde, como se viu antes, a 15 vezes o módulo médio regional $^{18}$, calculado de acordo com a tabela de módulos fiscais municipais em vigor. Assim, os limites de área variam desde 279,3 hectares na região Sul até $1.155,2$ hectares na região Norte. Na região Centro-Oeste, berço da agricultura de exportação, o limite de área é 650,7 hectares.

Uma parte destes agricultores possui, portanto, tamanho suficiente para desenvolver uma agri-

18 Deste modo, procurou-se estabelecer uma aproximação com o que dispõe a legislação, tendo em vista que o limite máximo legal da média propriedade é de 15 módulos fiscais. cultura moderna, empresarial, com escala de produção e, nesse sentido, pode se apropriar dos ganhos gerados pelas principais cadeias do agronegócio (complexo soja, fruticultura, lácteos etc.). São parecidos com os do modelo do "familyfarm" americano. Outros se restringem a participar das cadeias de produtos alimentares, contribuindo também com o aumento na participação no Valor Bruto da Produção, como foi enunciado acima. E existem também, sem dúvida, aqueles de subsistência, mais parecidos com os camponeses do que com os agricultores familiares empresariais antes descritos.

As variações mais expressivasna participação da agricultura familiar foram registradas nas regiões Norte e Nordeste, onde esse segmento passou a dominar a produção agropecuária, provavelmente em função também do efeito das políticas públicas (Pronaf, PCPRs etc.). A Tabela 2 mostra a participação regional da agricultura familiar.

Nas outras regiões, ou a participação na produção caiu um pouco (Sul, Sudeste e Centro-Oeste), em termos relativos. Mas a manutenção de praticamente a mesma participação relativa não significa que tenha havido estagnação deste segmento de agricultores. Pelo contrário, como foi nestas regiões (Sul e Centro-Oeste) onde se verificou o mais acentuado boom do agronegócio, manter a quase a mesma participação significa 
que a agricultura familiar cresceu praticamente no mesmo ritmo que a não familiar (patronal), também no seio do agronegócio, ou seja, acompanhou esse boom.

No entanto, nem todos os dados são positivos. Os dados das tabulações especiais do IBGE para o quesito fundiário revelam que, dentro da agricultura familiar, existe também certo grau de concentração fundiária. Tem-se um pequeno grupo de $17 \%$ do total dos agricultores familiares que possuem entre 50 e 100 hectares e mais de 100 hectares. Esse grupo concentra em suas mãos $63 \%$ da terra pertencente aos agricultores familiares e, pelo menos em algumas regiões, responde pela maior parte da produção de origem familiar. São os produtores gaúchos e paranaenses de soja e trigo, os produtores de leite de Minas, os produtores catarinenses de milho e aves, os produtores de fruta do Nordeste etc. Esse grupo, composto por aproximadamente 600.000 produtores, é o mais parecido que existe no Brasil com o familiyfarm dos EEUU, ou com os paysants franceses ou alemães.

Existe um grupo relativamente numeroso, $39 \%$ do total, que possui apenas 3\% do total da área e que trabalha em terras com menos de cinco hectares. A contribuição desse grupo à produção total é insignificante - são produtores de subsistência - dada a exiguidade de terras e de tecnologia, o que revela que existe um problema fundiário ainda a ser resolvido no Brasil. Trata-se de ampliar a área de terra e de outros fatores (água, educação etc.), como pré-condição básica para superação da pobreza.

Por motivos diversos, entre os quais a inviabilidade técnico-econômica desses estabelecimentos, os setores de menor área têm diminuído tanto em número quanto em terra, sejam familiares ou não familiares.

Embora a participação da agricultura familiar na produção seja da ordem de $40 \%$, como se viu na primeira parte deste trabalho, essa participação e sua evolução variam conforme se tratade produção pecuária, vegetal permanente ou de lavouras temporárias. Na Tabela 4 segue a evolução entre 1996 e 2006 dos percentuais de produção de origem animal dos agricultores familiares é apresentada.

Os dados mostram uma nítida tendência à queda da participação na produção pecuária de corte (bovinos, aves e suínos) realizada em moldes familiares, o que é coerente com a baixa disponibilidade de terra que eles possuem em relação aos não familiares para desenvolver uma atividade extensiva como esta. Os dados revelam, no entanto, um aumento na participação na

Tabela 3. Distribuição da terra dos agricultores familiares - Brasil - 2006.

\begin{tabular}{lcc}
\hline \multicolumn{1}{c}{ Estratos de área (ha) } & \% do $\mathbf{n}^{\mathbf{0}}$ de estabelecimentos & \% do total de área \\
\hline Menos de 5 & 39 & 3 \\
De 5 a menos de 20 & 20 & 13 \\
De 20 a menos de 50 & 16 & 21 \\
De 50 a menos de 100 & 7 & 20 \\
Mais de 100 & 10 & 43 \\
\hline Fonte: Elaboração própria com base em IBGE, censos agropecuários 1995-1996 e 2006. Tabulações especiais.
\end{tabular}

Tabela 4. Participação percentual do valor de produção de produtos de origem animal da agricultura familiar - Brasil - 1996-2006.

\begin{tabular}{lll}
\hline \multicolumn{1}{c}{ Tipo de produção } & $\mathbf{1 9 9 6}$ & $\mathbf{2 0 0 6}$ \\
\hline Pecuária de corte & 23,64 & 16,65 \\
Pecuária de leite & 52,05 & 60,53 \\
Suínos & 58,46 & 52,45 \\
Aves & 39,86 & 30,34 \\
\hline
\end{tabular}

Fonte: Elaboração própria com base em IBGE, censos agropecuários 1995-1996 e 2006.Tabulações especiais. 
produção de leite que sempre foi tradicionalmente uma atividade de ocupação de agricultores familiares.

A participação da agricultura familiar no plantio e produção de produtos da lavoura permanente, ao contrário dos anteriores, aumentou nesses últimos dez anos, pelo menos para os produtos selecionados, como se pode observar na Tabela 5.

Esses aumentos podem refletir tanto elevações de produtividade quanto de área, sendo que, se este for o caso, podem também sinalizar uma tendência de substituição de produtos de origem animal por produtos da agricultura, que são mais adequados ao grau de disponibilidade de fatores da agricultura familiar - pouca terra e muita mão de obra.

No caso da banana, cuja participação na produção total, esse dado parece mostrar o avanço da produção em perímetros de irrigação de vários estados do Nordeste, que privilegiaram esse produto e também privilegiaram os agricultores familiares nesses últimos dez anos.
A tendência à substituição na pauta produtiva da agricultura familiar aparece bem mais definida na Tabela 6, que mostra a evolução da participação na produção dos produtos da lavoura temporária. Os produtos que tiveram aumentos mais expressivos em sua participação foram registradosem ordem de importância: arroz (com quase 10 pontos percentuais de aumento), feijão e milho. As áreas de fumo e mandioca não tinham mais como aumentar, já que a agricultura familiar controla quase totalmente esse tipo de produção.

Fica assim configurada uma virada bastante significativa dos agricultores familiares para os produtos de alimentação, ou de produção doméstica, como também são conhecidos: arroz, milho, feijão e mandioca, com redução significativa dos produtos de origem animal.

Isto não implica que produtos característicos do agronegócio tenham sido abandonados pela agricultura familiar, que, apesar da queda, ainda mantém uma participação bastante razoável na produção de soja $(23,60 \%)$, de trigo $(36,38 \%)$ e dos produtos da pecuária de corte $(16,65 \%)$, que antes

Tabela 5. Participação percentual do valor de produção de produtos da lavoura permanente da agricultura familiar - Brasil - 1996-2006.

\begin{tabular}{|c|c|c|}
\hline Produto & 1996 & 2006 \\
\hline Banana & 57,58 & 62,40 \\
\hline Café & 25,47 & 29,67 \\
\hline Laranja & 26,96 & 25,25 \\
\hline Uva & 47,02 & 53,63 \\
\hline
\end{tabular}

Tabela 6. Participação percentual do valor de produção de produtos da lavoura temporária da agricultura familiar - Brasil - 1996-2006.

\begin{tabular}{|c|c|c|}
\hline Produto & 1996 & 2006 \\
\hline Arroz & 30,87 & 39,19 \\
\hline Cana-de-Açúcar & 9,55 & 10,24 \\
\hline Cebola & 72,37 & 69,59 \\
\hline Feijão & 67,23 & 76,57 \\
\hline Fumo & 97,18 & 95,67 \\
\hline Mandioca & 83,88 & 93,17 \\
\hline Milho & 48,57 & 51,90 \\
\hline Soja & 31,62 & 23,60 \\
\hline Trigo & 46,04 & 36,38 \\
\hline
\end{tabular}


mostramos, e de suínos (52\%). Ou seja, alguns segmentos mais capitalizados da agricultura familiar estão inseridos no agronegócio e produzem soja, trigo, gado e até cana-de-açúcar, enquanto que uma grande massa de agricultores familiares produz basicamente os alimentos.

Produzir alimentos, como arroz, feijão ou mandioca, não quer dizer necessariamente que esses produtores sejam camponeses ou "produtores de subsistência". Hoje em dia, produz-se arroz e feijão em bases familiares, com alta tecnologia e de forma totalmente voltada para o mercado, isto é, são produtores comerciais tanto quanto os que produzem soja, porque seu objetivo fundamental não é se alimentar, mas vender, com o que contribuem, por sua vez, com a segurança alimentar do Brasil.

Pode-se dizer, portanto, que a agricultura familiar participou de alguma forma do boom do agronegócio nos 2000 e também preservou seu papel de produtora comercial de produtos de consumo doméstico.

Outros segmentos da agricultura familiar produzem basicamente para autoconsumo, como os caboclos do sertão nordestino que não têm condições de se integrar positivamente nos mercados, o que não é nenhum demérito em relação à sua condição social, uma vez que, ao invés de migrar para o Sul e contribuir com o inchaço das cidades, penam para sobreviver o mais dignamente possível nas regiões pouco favorecidas onde nasceram.
O aumento na produção de lavouras permanentes, como dissemos anteriormente, ocorreu principalmente na região Nordeste, onde houve um esforço governamental e privado de incentivar os perímetros de irrigação com a produção de banana, laranja, uva e coco em bases familiares.

São conhecidos os esforços das empresas vitivinícolas de Petrolina, Santa Maria de Boa Vista e Juazeiro (PE) em tentar integrar os produtores familiares nos projetos de produção de uva.

\section{Mudanças em variáveis tecnológicas da agricultura familiar}

Como veremos a seguir, algumas questões que dizem respeito à adoção de tecnologias foram incorporadas por parcelas expressivas da agricultura familiar, principalmente no que diz respeito ao acesso à energia elétrica, que mais do que duplicou no período de análise e no uso de mecanização com progressivo abandono da agricultura tradicional "de enxada". Esse avanço pode se apreciar na Tabela 7.

Os dados da Tabela 7 mostram que estes avanços não se deram necessariamente por influência da assistência técnica, que evoluiu pouco no atendimento dos agricultores familiares. O novo censo registra que apenas $20,88 \%$ dos agricultores familiares teriam recebido assistência técnica em 2006, contra 16,67\% em 1996.

Pode ser que por este motivo não tenham sido registrados avanços no uso de adubos e corretivos

Tabela 7. Proporção dos agricultores familiares que usam componentes relativos à modernização da agricultura Brasil - 1996-2006.

\begin{tabular}{lcc}
\hline \multicolumn{1}{c}{ Variáveis selecionadas } & $\mathbf{1 9 9 6} \mathbf{( \% )}$ & $\mathbf{2 0 0 6}(\boldsymbol{\%})$ \\
\hline Utiliza assistência técnica & 16,67 & 20,88 \\
Associado à cooperativa & 12,63 & 4,18 \\
Usa energia elétrica & 36,63 & 74,1 \\
Usa força animal & 22,67 & 38,75 \\
Usa força mecânica & 27,5 & 30,21 \\
Usa força manual & 49,83 & 31,04 \\
Usa irrigação & 4,92 & 6,23 \\
Usa adubos e corretivos & 36,73 & 37,79 \\
\hline
\end{tabular}

Fonte: Elaboração própria com base em IBGE, censos agropecuários 1995-1996 e 2006. Tabulações especiais. 
Tabela 8. Variação percentual de componentes relacionados à modernização da agricultura familiar Brasil e regiões - 1996-2006.

\begin{tabular}{lcccccc}
\hline \multicolumn{1}{c}{ Brasil e regiões } & Assist. técnica & Assoc. coop. & Energ. elétrica & Tração mecânica & Irrigação & Adubos \\
\hline Norte & 177 & -67 & 409 & 134 & 391 & 30 \\
Nordeste & 192 & -87 & 270 & 24 & 43 & 26 \\
Sudeste & 19 & -75 & 63 & -10 & 17 & -5 \\
Sul & 0 & -60 & 13 & 10 & -3 & -4 \\
Centro-Oeste & 35 & -74 & 129 & 11 & 60 & 28 \\
Brasil & 27 & -66 & 105 & 4 & 4 \\
\hline
\end{tabular}

Fonte: Elaboração própria com base em IBGE, censos agropecuários 1995-1996 e 2006. Tabulações especiais.

e no processo associativista, que seriam dois fortes eixos de um processo de assistência técnica.

Os maiores avanços se deram no uso de energia elétrica, que foi realmente muito impulsionado pelo programa Luz para Todos, sobretudo no Nordeste, e na adoção de tração mecanizada vis à vis a tração manual. Esta tecnologia foi incentivada pelo Moderfrota do BNDES e pelo próprio Pronaf.

Ao se analisar este assunto com base nas taxas de crescimento, verifica-se que, embora a assistência técnica não tenha avançado muito em termos agregados (passou de 16,67\%, em 2006, para $20,88 \%$, em 2006 , em termos nacionais), em algumas regiões fizeram-se esforços significativos para aumentar sua influência juntos aos agricultores familiares. Nas regiões Norte e Nordeste, onde em 1996 apenas entre 3\% e 6\% dos agricultores tinha acesso à Assistência técnica e extensão rural (Ater), houve um avanço importante (177\% na região Norte e $192 \%$ no Nordeste). Isso significa que, em 2006, considerando-se estas taxas de crescimento, um grupo de aproximadamente $9 \%$ deve ter acesso à Ater no Norte e em média $18 \%$ no Nordeste.

Registram-se avanços importantes também na irrigação no Nordeste que, como se viu antes, foi objeto de amplos programas de irrigação pública e privada (Petrolina, Juazeiro etc.) e no uso de energia elétrica, que permitiu que nas regiões Norte e Nordeste se ampliasse expressivamente sua cobertura.

Chama a atenção o decréscimo acentuado e generalizado no que se considera "associado à cooperativa". Isto pode refletir algum problema de interpretação da pergunta, que pode ter excluído a questão das associações, restringindo somente a pergunta ao tema "cooperativa", ou pode refletir, então, algum fenômeno real, como a diminuição das cooperativas de leite em função do processo de concentração que houve nesse segmento produtivo, que acabou sendo acelerado pela lei que obriga o resfriamento do leite em todas as unidades produtivas antes de sua entrega.

\subsection{Diferenciais de produtividade}

No trabalho anterior, conhecido com "FAO-Incra", já tinha sido constatado que havia uma diferença forte de produtividade da terra entre os chamados patronais e os familiares. Essa diferença, que é bastante estudada pela bibliografia internacional ${ }^{19}$, reaparece neste estudo sobre o censo de 2006, como pode se apreciar na Tabela 9.

Percebe-se, pelos dados expostos acima, que a agricultura familiar, ao somar o valor de todos os produtos que produz numa certa área (VBP/ área), obtém R\$ 554 por hectare, em média 17\% a mais de produto que os não familiares (que são mormente os patronais) que geravam um VBP por hectare de R\$ 461 em 2006. No censo de 1996, essa diferença, ou superioridade, era de $39 \%$, ou seja, diminuiu bastante.

Os agricultores familiares, como foi constatado pela bibliografia internacional, fazem uso mais intensivo do fator terra por ser este o seu fator mais escasso e, por isso, devem explorar ao máximo a pouca quantidade de terra que possuem.

\footnotetext{
19 Ver sobre esse tema: Griffin (2002), Lund e Hill, (1979) e Binswanger (1978).
} 
Tabela 9. Produtividade por hectare comparada entre familiares e não familiares - Brasil - 1996-2006.

\begin{tabular}{lcc}
\hline \multicolumn{1}{c}{ Variáveis } & $\mathbf{1 9 9 6}$ & $\mathbf{2 0 0 6}$ \\
\hline VBP/Área Familiar & 435,12 & 554,57 \\
VBP/Área Não Familiar & 312,45 & 461,74 \\
\hline
\end{tabular}

Valores em reais constantes, atualizados com base no IGP-DI.

Fonte: Elaboração própria com base em IBGE, censos agropecuários 1995-1996 e 2006. Tabulações especiais.

Tabela 10. Produtividade da mão de obra comparada entre familiares e não familiares - Brasil - 1996-2006.

\begin{tabular}{lcc}
\hline \multicolumn{1}{c}{ Variáveis } & $\mathbf{1 9 9 6}$ & $\mathbf{2 0 0 6}$ \\
\hline Familiares: VBP/pessoal ocupado & $1.314,77$ & $4.538,71$ \\
Não Familiares: VBP/pessoal ocupado & $7.150,38$ & $29.762,92$ \\
\hline
\end{tabular}

Valores em reais correntes.

Fonte: Elaboração própria com base em IBGE, censos agropecuários 1995-1996 e 2006. Tabulações especiais.

Tabela 11. Percentual do financiamento totalrecebido segundo otipo de agricultor - Brasil - 1996-2006.

\begin{tabular}{|c|c|c|}
\hline Tipo de agricultor & 1996 & 2006 \\
\hline Familiar & 25,3 & 28,9 \\
\hline Não familiar & 74,7 & 71,1 \\
\hline
\end{tabular}

Fonte: Elaboração própria com base em IBGE, censos agropecuários 1995-1996 e 2006. Tabulações especiais.

O fator escasso dos não familiares (ou patronais) é a mão de obra, e por isso usam-na de forma mais intensiva como revela a Tabela 10.

Os dados dos censos agropecuários mostram que os rendimentos extraídos em termos de valor da produção do pessoal ocupado dos não familiares são de cinco a seis vezes maiores que os dos familiares.

Os agricultores familiares usam a mão de obra familiar de forma extensiva, com baixa produtividade por pessoa, já que seu objetivo é manter todos os membros da família ocupados, embora com salários ou rendas baixas. Os não familiares, como não dispõem de membros das famílias em abundância, para dar conta de áreas grandes, são obrigados a contratar empregados e, por esse motivo, devem ser mais eficientes no seu uso.

Ainda faltaria verificar o desempenho de cada categoria em relação ao uso do terceiro fator, o capital. Os dados de 1996 mostravam que, também neste caso, por se tratar do fator escasso dos familiares, esse fator era mais bem aproveitado entre os familiares do que entre os não familiares. A Tabela 11 ilustra a este respeito.

Nesta Tabela 11, pode-se perceber que houve um aumento dos financiamentos obtidos pelos agricultores familiares entre 1996 e 2006, passando de $25 \%$ para $29 \%$ do total ofertado aos agricultores pelos bancos oficiais e privados, o que deve refletir provavelmente o impulso dado pelo Pronaf aos agricultores familiares no mesmo período.

No tocante à análise de produtividades que estava se fazendo antes, percebe-se que, também neste caso, os familiares são mais produtivos: com menos financiamento em proporção ao total $(29 \%)$, produzem $36,11 \%$ do total do VBP, o que implica maior produção com menos financiamento, ou, em outras palavras, melhor aproveitamento do crédito e maior produção por unidade de capital aplicado ${ }^{20}$.

Gerar maiores rendimentos por área total, entretanto, não significa que a eficiência técnica dos familiares seja superior à de outros em cultivos específicos ou em áreas limitadas dentro do espaço de que dispõem. Se compararmos os rendimentos de um cultivo específico numa área limitada, certamente os não familiares mostrarão maiores rendimentos técnicos (soja por hectare,

\footnotetext{
${ }^{20}$ Helfand (2010) chega a conclusões similares em trabalho que usa PTF (produtividade total dos fatores). Na parte do capital as conclusões diferem porque ele utiliza dados de patrimônio ao invés de crédito, como foi feito neste trabalho.
} 
por exemplo). Ao somar todos os produtos e valorizá-los, o fenômeno da maior produtividade surge, porque os familiares não podem se dar ao luxo de deixar áreas sem explorar, o fazem de diversas maneiras e com vários produtos, enquanto que os grandes produtores às vezes escolhem uma parte boa de terra para plantar e deixam outras em repouso, ou com gado criado de forma extensiva, o que acaba dando baixa produtividade econômica da área total.

Tabela 12. Comparativo da produtividade por hectare entre familiares e não familiares - Brasil e regiões - 2006.

\begin{tabular}{lcc}
\hline \multirow{2}{*}{ Brasil e regiões } & \multicolumn{2}{c}{ Valor produzido por hectare (R\$ de 2006) } \\
\cline { 2 - 3 } & Não familiar & familiar \\
\hline Norte & 111,3 & 241,0 \\
Nordeste & 378,3 & 390,7 \\
Sudeste & $1.054,6$ & 737,8 \\
Sul & 837,3 & $1.337,6$ \\
Centro-Oeste & 271,7 & 285,1 \\
Brasil & 461,7 & 554,6 \\
\hline
\end{tabular}

Fonte: Elaboração própria com base em IBGE, censos agropecuários 1995-1996 e 2006. Tabulações especiais.

Tabela 13. Produtividade por hectare da mão de obra dos familiares -Brasil e regióes - 1996-2006.

\begin{tabular}{lcc}
\hline \multirow{2}{*}{ Brasil e regiões } & \multicolumn{2}{c}{ Valor produzido por hectare (R/ha) } \\
\cline { 2 - 3 } & 1996 & 2006 \\
\hline Norte & 160,10 & 241,00 \\
Nordeste & 230,10 & 390,70 \\
Sudeste & 557,80 & 737,80 \\
Sul & $1.142,50$ & $1.337,60$ \\
Centro-Oeste & 212,20 & 285,10 \\
Brasil & 435,10 & 554,60 \\
\hline
\end{tabular}

Fonte: Elaboração própria com base em IBGE, censos agropecuários 1995-1996 e 2006. Tabulações especiais.

Figura 1. Evolução comparada da utilização de mão de obra por hectare.

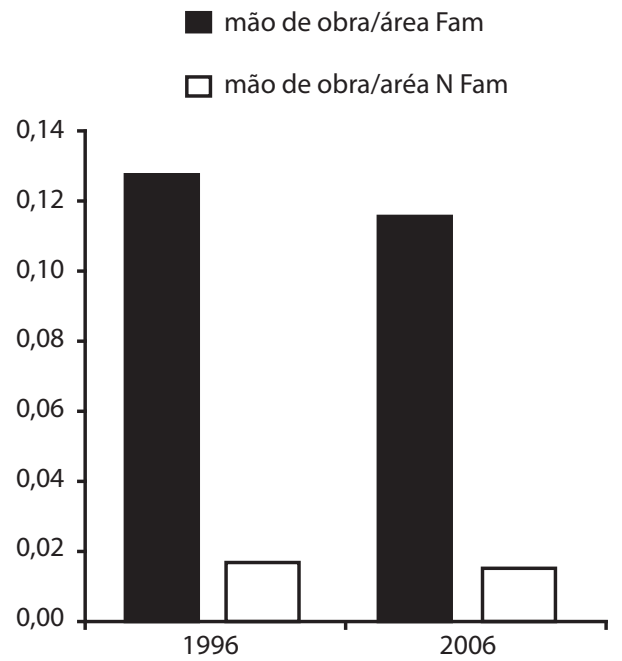

Fonte: Elaboração própria com base em IBGE, censos agropecuários 1995-1996 e 2006. Tabulações especiais. 
Obviamente, muitos agricultores não familiares, sobretudo os de soja do Centro-Oeste, não desperdiçam seu espaço agrícola e usam-no com alta tecnologia e eficiência, mas, no agregado do País, ao juntar todos os estabelecimentos não familiares e compará-los com os familiares, a superioridade dos últimos aparece claramente e para quase todas as regiões, como se verá em tabelas regionalizadas mais adiante.

Mas, como dissemos antes, a produtividade do trabalho é inferior entre os familiares, que preferem manter seus filhos empregados, a baixo custo e com baixa produtividade, a deixá-los buscar emprego nas cidades. A Figura 1 a seguir mostra que os agricultores familiares empregam em torno de 1/10 de um trabalhador por hectare (incluindo os da família e os contratados), enquanto que os não familiares não chegam a 0,2 de um trabalhador por hectare, ou seja, cinco vezes menos que os primeiros.

A Tabela 12 ilustra o desempenho dos estabelecimentos familiares em comparação com os não familiares para as cinco regiões do País.

Pode-se observar nos dados acima que, excetuando-se a região Sudeste, em todas as demais a produtividade da terra é maior entre os familiares que entre os não familiares. As regiões que têm essa diferença mais acentuada são Norte e Sul. Esta última é famosa pela predominância de agricultores familiares em várias cadeias produtivas que agregam bastante valor, como a avicultura, suinocultura, fumo etc. A região Norte tem contingentes expressivos de agricultores familiares oriundos dos projetos de colonização dos anos 1970, que são os que produzem a maior parte dos alimentos da região.

No Sudeste, entretanto, os empreendimentos capitalistas de alta tecnologia agrícola conseguem superar a força numérica dos agricultores familiares.

Cabe destacar, finalmente, que os rendimentos da terra têm evoluído favoravelmente entre os familiares de 1996 para 2006, como mostram a Tabela 13.

\section{Tipologia de agricultores familiares por renda}

A agricultura familiar no Brasil está composta de diversos subsegmentos que devem ser identificados para que se possa pensar com mais precisão em políticas diferenciadas em relação a este setor.

Nos trabalhos FAO/Incraoriginais chamava-se esses setores de: consolidados, em transição e periféricos. Uma classificação mais apurada do ponto de vista sociológico nomearia os três grandes subsegmentos como: agricultores familiares empresariais, agricultores familiares não empresariais e camponeses (SCHNEIDER, 2010). Tanto os primeiros quanto os segundos podem ser alvo de políticas tipicamente agrícolas (crédito, preços, por exemplo), enquanto os últimos camponeses frequentemente alijados do mercado - beneficiam-se mais de políticas agrárias, de educação e saúde do que de políticas agrícolas.

Para fins estatísticos, decidimos em 1996 classificá-los em função da renda total (RT) obtida por esses subsegmentos ${ }^{21}$.

Dividiu-se o universo dos agricultores familiares em função do que chamávamos de "custo de oportunidade do trabalho" que era, segundo a visão do FAO/Incra em 1996, o valor da diária regional, mais $20 \%$. Esse valor era chamado de V, sendo que os grupos criados oscilariam em torno do $\mathrm{V}$ da seguinte forma:

\begin{tabular}{|c|c|}
\hline Tipo & \\
\hline $\mathrm{A}$ & $\mathrm{RT}>3 \mathrm{~V}$ \\
\hline $\mathrm{B}$ & $\mathrm{V}<\mathrm{RT} \leq 3 \mathrm{~V}$ \\
\hline $\mathrm{C}$ & $\mathrm{V} / 2<\mathrm{RT} \leq \mathrm{V}$ \\
\hline $\mathrm{D}$ & $\mathrm{RT} \leq \mathrm{V} / 2$ \\
\hline
\end{tabular}

Com base nestes critérios obtém-se a seguinte divisão do universo analítico em questão:

\footnotetext{
21 Uma classificação melhor poder-se-ia fazer tomando-se em consideração o patrimônio acumulado pelos estabelecimentos. Este critério, entretanto, não pôde ser seguido em função da decisão do IBGE em 1996 de retirar as perguntas referentes ao patrimônio do questionário do censo.
} 
Tabela 14. Número de agricultores familiares segundo os tipos - Brasil - 1996-2006.

\begin{tabular}{ccc}
\hline Tipos & $\mathbf{1 9 9 6}$ & $\mathbf{2 0 0 6}$ \\
\hline A & 406.291 & 452.750 \\
B & 993.751 & 964.140 \\
C & 823.547 & 574.961 \\
D & 1.915 .780 & 2.560 .274 \\
Total & 4.139 .369 & 4.551 .855 \\
\hline
\end{tabular}

Fonte: Elaboração própria com base em IBGE, censos agropecuários 1995-1996 e 2006. Tabulações especiais.

Tabela 15. Distribuição percentual dos tipos de renda da agricultura familiar - Brasil - 1996-2006.

\begin{tabular}{ccc}
\hline \multirow{2}{*}{ Tipos familiares } & \% de estabelecimentos s/ total geral \\
\cline { 2 - 3 } & 1996 & 2006 \\
\hline A & 8,40 & 8,70 \\
B & 20,40 & 18,60 \\
C & 16,90 & 11,10 \\
D & 39,40 & 49,50 \\
Total & 85,10 & 87,90 \\
\hline
\end{tabular}

Fonte: Elaboração própria com base em IBGE, censos agropecuários 1995-1996 e 2006. Tabulações especiais.

Tabela 16. Participação no Valor Bruto da Produção (VBP) por tipo de renda da agricultura familiar - Brasil - 1996-2006.

\begin{tabular}{ccc}
\hline \multirow{2}{*}{ Tipos familiares } & \multicolumn{2}{c}{$\%$ s/ Total VBP familiares } \\
\cline { 2 - 3 } & 1996 & 2006 \\
\hline A & 50,6 & 69,5 \\
B & 29,3 & 15,7 \\
C & 9,4 & 4,7 \\
D & 10,7 & 10,1 \\
Total & 100,0 & 100,0 \\
\hline
\end{tabular}

Fonte: Elaboração própria com base em IBGE, censos agropecuários 1995-1996 e 2006. Tabulações especiais.

Tabela 17. Renda monetária líquida anual por tipo de agricultor familiar - Brasil - 1996-2006.

\begin{tabular}{lcc}
\hline \multirow{2}{*}{ Tipos de agricultor } & \multicolumn{2}{c}{ Renda monetária líquida anual* (R\$ de 2006) } \\
\cline { 2 - 3 } & 1996 & 2006 \\
\hline Familiares tipo A & $30.333,00$ & $53.236,00$ \\
Familiares tipo B & $5.537,00$ & $3.725,00$ \\
Familiares tipo C & $1.820,00$ & $1.499,00$ \\
Familiares tipo D & $-265,14$ & 255,00 \\
Patronais & & $70.903,00$ \\
\hline
\end{tabular}

*Descontados os custos de produção, mas não descontada a depreciação. Valores de 1996 atualizados pelo IGP-DI.

Fonte: Elaboração própria com base em IBGE, censos agropecuários 1995-1996 e 2006. Tabulações especiais.

Pela Tabela 14 percebe-se claramente que existe um grupo forte dentro da agricultura familiar, composto por um pouco mais de 400.000 produtores gerando acima de $3 \mathrm{~V}$ por mês de renda total, mas que existem outros grupos de menor renda que têm aumentado sua importância relativa, principalmente o grupo $\mathrm{D}$, que abrange os mais pobres da agricultura familiar, e que alguns chamam de camponeses ou periféricos.

A Tabela 15 mostra o avanço dos periféricos (grupo D) em percentuais.

Nos 10 anos em análise (1996/2006) o número e a participação percentual do segmento mais pobre da agricultura familiar aumentarama 
custas de reduções dos segmentos intermediários ou de transição (B e C).

O fortalecimento do grupo A e o empobrecimento dos outros grupos têm sua origem em formas diferentes de participação na produção agropecuária, como revela a Tabela 16.

Os dados da Tabela 16 mostram um grande crescimento da participação na produção do grupo A, que passou, nesses dez anos, de 50,6\% para $69,5 \%$ do total. Os grupos B e C caíram em termos percentuais e o grupo D manteve-se estabilizado, mas principalmente pelo aumento numérico que teve nesse período.

As mudanças nos valores produzidos ocasionam obviamente alterações na renda média obtida pelos estabelecimentos de cada grupo, como pode ser observado na Tabela 17.

Fica bem evidente na Tabela 17 que o gradiente de renda entre os grupos é grande e, além disso, aumentou entre 1996 e 2006. O grupo A, que está composto por aproximadamente 400.000 produtores, gera renda média anual bastante elevada, que equivale a quase $\mathrm{R} \$ 4.500$ por mês de ganho monetário. Ao se considerar que nas áreas rurais os produtores têm acesso a outras rendas não agrícolas, asquase-rendas (como o autoconsumo) e que não pagam aluguel, o valor equivale a um padrão de vida de classe média urbana. Este grupo é o mais semelhante, na agricultura brasileira, ao "familyfarm" norte-americano.

Cabe notar, entretanto, que entre o grupo A e os outros grupos há uma distância que varia entre 200 vezes (com o grupo D) até 14 vezes (grupo B), e que esta distância tem aumentado entre 2006 e 1996.

Buscando explicações para este fenômeno temos escolhido quatro possíveis variáveis explicativas: área média, condição do produtor, especialização e acesso ao Pronaf.

Vejamos o que acontece com a primeira dessas variáveis, o tamanho médio da área.

Tabela 18. Área média dos estabelecimentos familiares por tipo de renda - Brasil - 1996/2006.

\begin{tabular}{ccc}
\hline \multirow{2}{*}{ Tipos familiares } & \multicolumn{2}{c}{ Área média (ha) } \\
\cline { 2 - 3 } & 1996 & 2006 \\
\hline A & 59 & 48 \\
B & 34 & 26 \\
C & 22 & 21 \\
D & 16 & 19 \\
Total & 26 & 23 \\
\hline
\end{tabular}

Fonte: Elaboração própria com base em IBGE, censos agropecuários 1995-1996 e 2006. Tabulações especiais.

Tabela 19. Condição de acesso à propriedade dos tipos de renda dos familiares - Brasil - 1996-2006.

\begin{tabular}{|c|c|c|}
\hline Anos & Proprietários (\%) & Não proprietários $(\%)$ \\
\hline \multicolumn{3}{|c|}{ Média dos familiares } \\
\hline 1996 & 75 & 25 \\
\hline 2006 & 75 & 25 \\
\hline \multicolumn{3}{|l|}{ Tipo A } \\
\hline 1996 & 89 & 11 \\
\hline 2006 & 83 & 17 \\
\hline \multicolumn{3}{|l|}{ Demais tipos } \\
\hline 1996 & 75 & 25 \\
\hline 2006 & 74 & 26 \\
\hline
\end{tabular}

Fonte: Elaboração própria com base em IBGE, censos agropecuários 1995-1996 e 2006. Tabulações especiais. 
Tabela 20. Grau de especialização ou diversificação da produção familiar- Brasil - 1996-2006.

\begin{tabular}{ccc}
\hline Anos & Especializados (\%) & Diversificados (\%) \\
\hline Média familiar & & \\
\hline 1996 & 41 & 59 \\
2006 & 56 & 44 \\
\hline Tipo A & & \\
\hline 1996 & 51 & 49 \\
2006 & 72 & 28 \\
\hline
\end{tabular}

Fonte: Elaboração própria com base em IBGE, censos agropecuários 1995-1996 e 2006. Tabulações especiais.

Observa-se primeiramente que a área média em geral é bastante baixa, próxima do que se convenciona chamar de pequeno produtor. $\mathrm{O}$ grupo A, entretanto, possuiárea mais avantajadae, como se trata de uma média, pode estar incluindo produtores de áreas relativamente grandes (500 ha), mas que produzem predominantemente com base no trabalho familiar.

O gradiente de área, entre os diferentes grupos de renda, no entanto, não é muito grande, não chegando a duas vezes entre os grupos A e D, enquanto as diferenças de renda eram de 200 vezes entre estes grupos ${ }^{22}$.

Conclui-se, portanto, que a quantidade ${ }^{23}$ de terra possuída não influi decisivamente na renda gerada pelos produtores.

Vejamos na Tabela 19 se a condição do produtor explica esse gradiente.

Fica claro novamente que esta variável, a da terra, em sua condição jurídica, tampouco explica os gradientes de renda. Os dados mostram que $83 \%$ dos estabelecimentos familiares do tipo A eram proprietários em 2006, enquanto na média dos demais grupos era de $75 \%$. Não há, portanto, nenhuma correlação evidente entre os diferenciais de renda entre os grupos - que chegavam a 200 vezes - com os diferenciais de terra ou de acesso à terra, que eram praticamente os mesmos entre os grupos citados.

${ }^{22}$ As diferenças entre as variáveis surgem a simples vista, não se fazendo necessário, portanto, proceder à análise econométrica, já que obviamente qualquer regressão entre as variáveis daria um grau de significância muito baixo.

${ }^{23}$ A qualidade e a localização da terra podem influenciar mais nessa diferença, mas o censo não fornece informações desse tipo (climas, solos, declividades) para efetuar essa correlação.
Para aprofundar a análise dos determinantes de renda, calculamos um índice de especialização produtiva - terceira variável antes citada - com base nos seguintes critérios:

Grau de Especialização: \% Valor da produção do produto principal/VBP

A-Superespecializado $=100 \%$

B-Especializado $=65 \% \leq 100 \%$

Especializados: soma de A e B

C-Diversificado $\quad=\quad 35 \% \leq 65 \%$

D-Muito diversificado $=\quad<35 \%$

Diversificados: soma de C e D

Aplicando-se estes parâmetros aos dados dos censos obtêm-se os seguintes resultados (ver Tabela 20):

Nota-se claramente que entre os dois censos houve uma tendência à especialização produtiva entre os familiares e, portanto, de diminuição da diversidade de sua produção.

O índice de especialização aumentou de $41 \%$ para $56 \%$, enquanto que o índice de diversificação caiu de $59 \%$ para $44 \%$. Isto quer dizer que o produto principal tende a ocupar espaço cada vez maiorno padrão de produção dos agricultores familiares, o que não é de seestranhar, dado o boom da soja e de outras commodities na última década.

Mas, no grupo A, esta tendência acelerou-se de forma mais acentuada, passando de $51 \%$ da produção com um só produto para $72 \%$, o que deixa este setor próximo do que chamamos de "superespecializado".

Dados suplementares do censo mostram que esta maior especialização ter-se-ia dado pela maior participação do grupo A na produção de lavouras permanentes, principalmente. São as produções de café, banana e uva. 
Tabela 21. Distribuição do Pronafpor categorias de crédito, em percentuais - Brasil - 1999-2004-2007.

\begin{tabular}{cccc}
\hline Categorías do Pronaf & $\mathbf{1 9 9 9}$ & $\mathbf{2 0 0 4}$ & $\mathbf{2 0 0 7}$ \\
\hline A & 21 & 8 & 4 \\
B & 1 & 7 & 6 \\
C & 22 & 25 & 15 \\
D & 48 & 37 & 40 \\
E & 12 & 12 & 20 \\
Outros & & 11 & 15 \\
\hline
\end{tabular}

O grupo A envolve os assentados de reforma agrária; os demais estão em ordem crescente de renda, ou seja, o E é o mais rico e o B, o mais pobre. Fonte: Dados extraídos de Mattei (2006) e Aquino (2009).

Embora esta variável pareça estar determinando de forma mais forte o aumento do gradiente de renda entre os grupos, resta avaliar a quarta das variáveis enunciadas acima, que é o papel do Pronaf no processo de geração e concentração de renda entre os grupos.

Para isto elaboramos a Tabela 21 com os dados de crédito rural (Pronaf) por categoria de crédito.

Percebe-se, na Tabela 21, que a proporção de recursos alocados aos produtores mais capitalizados (soma de grupo D e $\mathrm{E}=60 \%$ ) ao longo do período considerado corresponde a dez vezes o total de crédito dado aos mais pobres (grupo $\mathrm{B}=6 \%$ ), embora este último tenha melhorado sua participação no volume total em relação a 1999.

Em suma, pelo visto nesta seção, entre os quatro possíveis fatores explicativos dos gradientes de renda, dois mostraram-se irrelevantes - área e condição do produtor -, um foi relativamente significativo à simples vista - grau de especialização - e o quarto mostrou-se altamente correlacionado com renda. Embora as diferenças de renda fossem de 200 vezes e o diferencial de crédito seja de 60 vezes, há uma aparente correlação entre essas variáveis ${ }^{24}$.

Que os produtores mais capitalizados recebam maior proporção do crédito não é de se estranhar, já que estes produtores, além de serem mais capacitados - maior nível educacional - e capitalizados, sempre tiveram mais acesso à assistência técnica e às políticas agrícolas em geral.

${ }^{24}$ Uma análise econométrica mais aprofundada poderia trazer mais luz sobre essas correlações em termos regional e microrregional.
O que resulta surpreendente é que este diferencial tenha se aguçado neste período, no qual a ação do Pronaf podia tê-lo evitado.

Para garantir maior equidade na distribuição dos recursos públicos, o fomento via crédito de custeio (Pronaf) deveria ter sido acompanhado por outras linhas de crédito de investimento em infraestrutura do estabelecimento que fortalecessem de fato a capacidade de produzir e de elevar sua tecnologia e de atingir rendas mais elevadas. Além disso, os produtores intermediários - grupos B e C - deveriam ter sido acompanhados e capacitados permanentemente por meio de uma assistência técnica eficiente e sistêmica que lhes permitisse elaborar projetos em dessa formam ter acesso mais facilmente aos financiamentos.

Infelizmente, o Pronaf nesses anos ficou restrito praticamente ao crédito de custeio com algumas ações em termos de infraestrutura, mas de nível municipal, que não atingiram efetivamente os próprios agricultores.

Mais recentemente, o Pronafabriu linhas de crédito e apoio à comercialização (PAA), que podem ter efeitos positivos na renda dos agricultores no futuro, mas o capítulo da infraestrutura - com crédito de investimento - ainda está aquém das necessidades.

Cabe destacar, finalmente, a falta de focalização do Pronafnas cadeias produtivas. Por se tratar de um crédito de balcão, isto é, cada um destina o crédito para o que desejar, não houve possibilidade de reforçar algumas cadeias produtivas que apresentavam ou iriam apresentar com certeza certas deficiências, como, por exemplo, a pecuária de leite, que, em 
função da obrigatoriedade de resfriamento do leite, precisava de financiamentos focalizados e, sobretudo, de investimentos que garantissem esse processamento agora exigido por lei.

Ao não ter sido focalizado com crédito, esse tipo de cadeia produtiva ficou à margem do processo de integração e manifestou sua deficiência com a redução da produção de leite entre os familiares como se viu anteriormente.

\section{Conclusões}

Neste artigo mostramos inicialmente a participação dos familiares no conjunto da agricultura brasileira, se manteve praticamente inalterada ou com leve diminuição, passando de $37,9 \%$ do total produzido em 1996 para 36,11\% em 2006.

Houve uma melhora, embora não muito forte, na distribuição regional da agricultura familiar, que viu reforçada sua posição nas regiões Norte e Nordeste e manteve sua participação constante nas demais regiões.

A agricultura familiar também continua sendo mais eficiente no uso dos fatores terra e capital - financiamentos - o que é coerente com sua relativa escassez e necessidade, portanto, de usar esses fatores mais intensivamente, contrariamente ao uso do fator trabalho, que foi mais eficiente entre os agricultores patronais, para quem este fator é mais escasso.

Os dados mostraram por outro lado que subsistem as limitações tecnológicas e fundiárias entre os agricultores familiares de modo geral. Uma parcela significativa dos familiares possui pouca terra, fator esse que se verificou como um limitante na expansão de sua renda.

Do ponto de vista tecnológico verificou-se uma relativa melhora na utilização de tração animal e mecânica, mas um percentual ainda muito alto, mais de $30 \%$, trabalha usando exclusivamente a enxada como instrumento de aração da terra.

Um aspecto positivo foi o incremento no número de estabelecimentos com energia elétrica, produto, sem dúvida, dos programas governamentais, tais como Luz para Todos e Luz no Campo.
Em função da falta de focalização do Pronaf em cadeias produtivas e da ausência quase total de assistência técnica e de crédito de investimento, houve piora na distribuição de renda entre os grupos da agricultura familiar: cresceu em termos produtivos e de renda total o grupo dos consolidados (A) e decresceram os grupos em transição (B, e C) e periféricos (D).

Este fenômeno não pode ser explicado por maior acesso à terra ou por melhor condição de titulação, que são praticamente iguais entre os diversos grupos. Dois fatores foram preponderantes para que houvesse aumento de concentração nos grupos mais abastados da agricultura familiar (grupo A, de 400.000 produtores), que foram: a maior especialização do grupo A da agricultura familiar em poucos produtos de sucesso comercial e o maior acesso ao Pronafcusteio.

Aconteceu, em suma, exatamente o contrário do que se esperava quando se lançou o Pronaf, que trabalhava com a expectativa de tirar da miséria o grupo dos periféricos, evitando que os grupos em transição piorassem. No entanto, foram os grupos em transição os que engrossaram o grupo dos periféricos.

Para esse grupo não serão as políticas de crédito de custeio, por mais subsídio que se aplique, as que resolverão o problema de sua pobreza. Tratar-se-ia de implementar políticas específicas, focalizadas para esse grupo, como as de maior acesso a água, terra, educação. Em suma, trata-se de apoiar esse grupo mais com políticas agrárias e sociais do que com políticas agrícolas.

\section{Referências bibliográficas}

AQUINO, J. R. de. Avanços e Limites da Política de Crédito do Pronaf no Brasil (1996-2008): Uma Reflexão Crítica. In: XLVII Congresso da Sociedade Brasileira de Economia e Sociologia Rural -Sober, Porto Alegre, RS, 2009.

BINSWANGER, H. Agricultural and Rural development. World Bank paper.1994.

FRIEDMAN, H. Household Production and the National Economy. The Journal of Peasant Studies. v. 7, 1980, p. 158-180. 
GASSON, R., et al. The farm as a family business: a review. Journal of Agricultural Economics, Oxford, 39 (1). Jan. 1988, p. 1-43.

GRIFFIN, K., et al. Poverty and the Distribution of Land. Journal of Agrarian Change, v. 2 (3), 2002, p. 279-330.

GUANZIROLI, C. PRONAF: dez anos depois, uma avaliação. Revista da SOBER, 2. trim.2006.

GUANZIROLI, C., et al. Agricultura Familiar e Reforma Agrária no Século XXI. Rio de Janeiro:Garamond, 2001.

HELFAND, S. Explicando as diferenças na produtividade agrícola no Brasil. Niterói: Faculdade de Economia/ UFF, ago. 2010 (paper apresentado em Seminário do Programa de Pós-graduação em Economia/UFF).

LUND, P. J. e HILL, P. G. Farm Size, Efficiency and Economies of Size. Journal of Agricultural Economics, 30(2), may. 1979.
MATTEI, L. Impactos do PRONAF: Análise de Indicadores. Brasília: NEAD/MDA, 2005 (Série Estudos 11).

MDA. Relatório de Avaliação do Plano Plurianual 20082011. Brasília: Ministério de Desenvolvimento Agrário, 2008.

MDA/INCRA/FAO. Cardim, S. (INCRA) e Guanziroli, C. (FAO) (coord.). Novo Retrato da Agricultura Familiar: O Brasil Redescoberto. Brasília: Ministério do Desenvolvimento Agrário/Instituto Nacional de Colonização e Reforma Agrária, fev. 2000.

SCHNEIDER, S. Painel. In: XLVIII Congresso da Sociedade Brasileira de Economia e Sociologia Rural Sober, Campo Grande-MS, 2010.

STANTON, B. F. Perspective on Farm Size. Journal of Agricultural Economics, dec.1978. 